\title{
A CIÊNCIA COMO FORÇA PRODUTIVA E A CRISE DO CAPITAL
}

\author{
Rafael C. Rocha ${ }^{1}$
}

\section{Resumo}

Neste artigo, parte do terceiro capítulo da minha dissertação de mestrado, realizada sob orientação dos professores Theotonio dos Santos e Aluisio Bevilaqua discuto como, subsumida às relações capitalistas, a ciência se torna cativa do processo de valorização de capital. As implicações desse processo não se resumem à sua mercantilização na medida em que a produção científica vai além das esferas de busca e reprodução de conhecimento, mas diz respeito à reprodução da sociedade em geral. A ciência e educação não são apenas mercadorias, mas força produtivas e parte constitutiva da força de trabalho, respectivamente. Ambas ganham centralidade nesta nova fase da revolução industrial, disparada a partir da aplicação da inteligência artificial na automação da produção. À medida que o trabalho científico se torna a principal força produtiva social, incide a crise da erosão do tempo de trabalho como paradigma de mensuração de valor.

Palavras-chave: Crise; Ciência; Automação; Marx.

\section{Abstract}

In this article, part of the third chapter of my master's dissertation, conducted under the guidance of professors Theotonio dos Santos and Aluisio Bevilaqua, I discuss how, subsumed to capitalist relations, science becomes captive of the process of producing surplus-value. The implications of this process are not limited to its commodification insofar as scientific production goes beyond the spheres of search and reproduction of knowledge, but refers to the reproduction of society in general. Science and education are not just commodities, but productive forces and a constituent part of the labor force, respectively. Both gain centrality in this new phase of the industrial revolution, triggered by the application of artificial intelligence in the automation of production. As the

\footnotetext{
${ }^{1}$ Mestre em Políticas Públicas e Formação Humana pela Universidade do Estado do Rio de Janeiro (2018); UERJ; rafaelcrocha@gmail.com
} 
scientific work becomes the main social productive force, it inflicts the crisis of the erosion of working time as a paradigm of value measurement.

Keywords: Crisis; Science; Automation; Marx

\section{A ciência e a inovação no contexto do processo de produção de valor}

A especificidade do processo de trabalho no modo de produção capitalista é que o processo de produção de valores de uso, objetos destinados à satisfação das necessidades humanas, conforma uma unidade dialética com o processo de produção de valor, mensurado através do quantum de trabalho social contido em cada mercadoria. Enquanto a produção de valores de uso só é possível pelo caráter concreto do trabalho, o processo de produção de valor só faz sentido ao considerar-se o caráter abstrato do trabalho, justamente o que permite que as mais variadas atividades produtivas humanas possam ser comparadas e seus resultados intercambiados no mercado.

Esta contradição histórica desenvolvida pela relação-capital, manifesta no duplo caráter do trabalho (concreto e abstrato) e que se expressa na ambiguidade da forma mercadoria (valor de uso e valor de troca) tampouco é alheia à produção científica:

Ao mesmo tempo em que ela [ciência] é um momento do acúmulo de conhecimento humano, que pode ser traduzido em uma aplicação concreta (seu valor de uso), ela também é uma indústria, um departamento da produção capitalista, que só pode ter sua dinâmica explicada pelo processo de valorização do capital (seu valor de troca) (BEVILAQUA, 2015, p. 295).

Conforme observa Marx no fragmento dos Grundrisse dedicado às máquinas, "A invenção torna-se então um negócio e a aplicação da ciência à própria produção imediata, um critério que a determina e solicita" (MARX, 2011, p. 587).

Reconhecer a mercantilização da ciência e sua submissão à lógica da relação capital no processo de produção de valor não neutraliza o papel revolucionário do desenvolvimento tecnológico que media e transforma a relação entre os seres humanos e também entre estes e a natureza. 
O processo de reprodução de capital não pode ser satisfatoriamente examinado apenas pelo lado do valor de troca, por isso Marx abordou ambos os aspectos da mercadoria e do trabalho em sua análise. É na vitalidade dessa contradição, e no movimento que resulta da unidade dos contrários, que residem os efeitos que permitem vincular a produção científica à crise orgânica do capital.

Santos (1983) destaca o fato de que as mudanças tecnológicas afetam o caráter útil e concreto dos bens. São produzidas na vida material e não no plano mercantil. São um acúmulo da experiência produtiva do homem, do desenvolvimento da ciência e independem do modo de produção. 0 sistema não pode criar um conhecimento que não se submete à própria lógica do conhecimento. Isso não significa atribuir uma neutralidade à tecnologia. "0 capitalismo impulsiona as mudanças que favorecem o aumento da taxa de lucro" (p. 237-250).

A partir da lógica da análise econômica, Rosenberg (2006) refere-se ao debate em torno do papel econômico desempenhado pelo progresso científico-técnico no capitalismo:

A grande massa de escritos dos economistas sobre o tema [...] tanto teóricos, quanto empíricos se atém ao papel das mudanças técnicas na redução de custos. Essa redução ocorre, porque o desenvolvimento tecnológico aplicado à produção permite que com a mesma quantidade de capital investido se produza um volume maior de um dado produto (p. 18).

Apesar do discurso de muitos burgueses que se autointitulam beneficentes e que financiam diversas pesquisas de forma supostamente desinteressada, é fato que o investimento em ciência e tecnologia somente existe onde um retorno econômico esteja vislumbrado, direta ou ainda indiretamente, como no caso da pesquisa militar, esfera na qual, além do lucrativo mercado internacional, a supremacia possibilita o domínio de recursos e mercados. Se os problemas tecnológicos para se enviar um foguete à lua não fossem exatamente os mesmos que os para se enviar uma ogiva nuclear até outro continente através de uma trajetória balística, certamente a corrida espacial não teria a importância que teve durante a corrida armamentista nuclear no contexto da Guerra Fria, como demonstra o fato 
notável de nenhum ser humano ter pisado na lua desde 1972, mesmo ano em que os Estados Unidos e a União Soviética iniciaram as tratativas que levaram à assinatura do Tratado sobre Mísseis Antibalísticos (ABM), banindo novos desenvolvimentos na área e estabilizando o balanço de forças entre estas potências. Já o ressurgimento da indústria espacial na segunda década do século XXI está ligado à possibilidade de mineração de asteroides e a uma nova corrida armamentista no contexto do fim da hegemonia estadunidense ${ }^{2}$.

Isso não significa, como simplificam em demasia muitos economistas, algo notado por Rosenberg, que tudo que possa ser dito sobre o papel econômico da tecnologia esteja reduzido à sua capacidade de aumentar a produtividade e reduzir os custos de produção. Ele destaca um segundo efeito do avanço tecnológico tão importante quanto o de reduzir custos: a introdução de novos produtos e o aprimoramento de sua qualidade. Para este autor, "excluir do progresso técnico a inovação de produtos, especialmente quando se consideram longos períodos históricos, equivale a encenar Hamlet sem o príncipe" (ROSENBERG, 2006, p. 19). Isso complexifica sobremaneira a análise que deixa de ser apenas quantitativa e limitada a produtos que permanecem inalterados.

Há uma distinção fundamental entre esses dois efeitos do progresso tecnológico na economia: enquanto a redução de custos é algo ativamente buscado, o surgimento de novos ramos e produtos é algo que não pode ser previsto a priori dada a própria natureza da pesquisa científica. Assumimos que o desconhecido se comporta de forma similar ao conhecido, senão a ciência não seria possível, contudo, é justamente pelo fato de o desconhecido não ser igual ao conhecido que a ciência é necessária e as surpresas inevitáveis. Se a inovação buscada pode ser antevista na consciência humana é porque a descoberta que permite essa projeção já foi feita no passado e o trabalho agora é de viabilizá-la tornando seus custos factíveis. Quem poderia prever que os professores Andre Geim e Kostya Novosolev, da Universidade

\footnotetext{
2 Em 13 de junho de 2002, durante o governo Bush, os Estados Unidos se retiraram unilateralmente do Tratado ABM.
} 
de Manchester, descobririam o grafeno ao usarem fita adesiva para remover flocos de uma placa de grafite? Por outro lado, se não fosse óbvia a importância econômica da pesquisa em torno dos novos materiais, esta universidade não financiaria um Centro de Mesociência e Nanotecnologia onde ambos trabalhavam juntos. 0 fato é que hoje os laboratórios ao redor do mundo estão explorando o enorme potencial do grafeno, o material mais fino, leve, resistente e maleável conhecido até o momento.

Os resultados da pesquisa em ciência, seja ela de base ou aplicada, transpostos à produção podem resultar em novos produtos e também em novos processos. Kuznets observou que o fato de uma inovação dizer respeito a um produto ou a um processo é algo que depende muito da perspectiva que se adota. Rosenberg concorda e reforça:

As inovações de processo envolvem tipicamente equipamentos ou maquinário novos, nos quais tais inovações estão corporificadas; esse maquinário ou tais equipamentos constituem uma inovação de produto, do ponto de vista da firma que os produz (ROSENBERG, 2006, p. 19).

O autor cita o exemplo do conversor Bessemer, uma espécie de fornalha refratária que permite a produção em massa de aço, reduzindo enormemente o custo da produção. Esta era uma inovação de processo para os fabricantes de ferro e aço, mas uma inovação de produto para os fornecedores de equipamentos para a indústria.

Salvo algumas exceções, como uma nova forma de se fazer um cálculo de cabeça, que pode ser considerado uma tecnologia mental ou uma inovação organizacional, uma nova tecnologia está associada à construção de uma nova máquina ou à modificação de uma já existente. Mesmo novos programas de computador, que podem ser descritos como uma sequência de instruções lógicas que, por definição, poderiam ser rodados em qualquer máquina universal, na prática, exigem, por conta dos impactos dos limites de recursos nos tempos de execução, uma renovação constante dos equipamentos. Desta forma, a ubiquidade do sistema de máquinas quando falamos em desenvolvimento tecnológico e produção industrial permite que seu processo de conformação nos sirva de roteiro para entendermos as 
transformações históricas que o desenvolvimento tecnológico operou no capitalismo, a partir do entendimento, na esfera da produção de valor, da máquina como uma categoria econômica subsumida ao conceito de capital, como propõe Bevilaqua (2015), e também, na esfera da produção de valores de uso, da "história da formação dos órgãos produtivos do homem social", como reificação do corpo humano (MARX, 1996, l.1, v. 2, p. 8).

A construção das máquinas se torna o elo por excelência entre a ciência e a produção, pois é "a análise originada diretamente da ciência e a aplicação de leis mecânicas e químicas que possibilitam à máquina executar o mesmo trabalho anteriormente executado pelo trabalhador" (MARX, 2011, p. 587).

\section{A maquinaria, os órgãos sociais da produção subsumidos ao conceito de capital}

Para entendermos o surgimento da indústria a partir do materialismo histórico, é necessário compreendermos o fato, demonstrado por Bevilaqua (2016), de que no método de Marx a máquina deve ser entendida como uma categoria econômica subsumida ao conceito de capital, o que contrasta com a abordagem mais histórico-descritiva de Rosenberg. Deve-se, primeiramente, entender o papel da máquina nas transformações ocorridas no processo de produção de valores de uso, um papel que a distingue da ferramenta, pois se ao longo de todo o período pré-industrial da história da humanidade era a força de trabalho o ponto de partida do revolucionamento do modo de produção, na grande indústria este ponto de partida está no meio de trabalho (MARX, 1996, Livro 1, v. 2. p. 8). Em contraste com a ferramenta e mesmo com a manufatura, o sistema de máquinas relativiza todos os limites impostos pela natureza do corpo humano à produção, o que é um prérequisito para a aplicação extensiva e sistemática da ciência na produção.

O sistema de máquinas e a aplicação da ciência na produção ocorrem após um longo desenvolvimento do processo de trabalho, durante o qual este se torna cada vez mais social:

o desenvolvimento da força produtiva social do trabalho pressupõe cooperação em larga escala, como só com esse pressuposto é que podem: ser organizadas a divisão e a combinação do trabalho; poupados meios de produção mediante concentração maciça; criados materialmente meios de 
trabalho apenas utilizáveis em conjunto, por exemplo, sistema de maquinaria etc.; serem postas a serviço da produção colossais forças da Natureza; e pode ser completada a transformação do processo de produção em aplicação tecnológica da ciência (MARX, 1988, l. 1, v. 2 p. 255-256).

Já na perspectiva do processo de produção de valores, deve-se partir da concepção da máquina como capital constante em geral, ou seja, como trabalho morto objetivado, valor cristalizado. "Neste sentido, a máquina é um armazenador de trabalho vivo, que pode ser despendido em um outro ciclo produtivo" (BEVILAQUA, 2015, p. 256). Além disto, no processo de produção de valores, se revela uma nova função da máquina que demarca novamente sua distinção da ferramenta e que vai além da mera redução de custos. Conforme Marx nota, o móbil da burguesia ao investir no desenvolvimento da maquinaria é: "baratear a mercadoria e, mediante o barateamento da mercadoria, baratear o próprio trabalhador." (MARX, 1988, Livro 1, v. 1, p. 435).

Desta forma, a maquinaria aparece como produto da luta de classes, arma da burguesia contra o proletariado, o que está na base das razões históricas do surgimento do movimento de resistência dos ludistas. Prova disso é que seu emprego se dá primeiramente não nos locais onde a mão de obra era escassa, mas justamente na região da Inglaterra onde se concentrava um enorme exército industrial, o qual seu emprego regulava e disciplinava.

Da mesma forma, a luta interna entre a burguesia é fundamental para compreendermos a difusão das máquinas:

este papel só faz sentido ao observar-se a tendência à equalização da taxa de lucro entre os capitalistas que atuam em diversos ramos. A adoção das máquinas apenas se justifica em um mercado no qual se confrontam diversos capitalistas, sejam eles os primeiros industriais que expropriaram os tecelões de Lancashire no século XVIII, ou os grandes monopólios que nos dias de hoje travam guerras entre si. Sem isso a mecanização não se sustentaria; não seria possível a sobrevivência dos setores com alta composição orgânica se eles não fossem capazes, através das trocas desiguais, de se apropriarem da mais-valia produzida nos outros ramos, onde o uso do capital variável é mais intenso (BEVILAQUA, 2015, p. 257).

Isso explica por que a classe capitalista é a primeira classe dirigente na história cujos interesses estão indissoluvelmente ligados à mudança tecnológica e não à manutenção do status quo. Essa característica do modo 
de produção capitalista, que embutiu a constante renovação tecnológica à sua dinâmica econômica, levando à Revolução Industrial e às transformações que não encontram paralelo na história pós-neolítica, foi descrita por Marx e Engels na famosa passagem do Manifesto Comunista:

A burguesia não pode existir sem revolucionar continuamente os instrumentos de produção, portanto as relações de produção e, assim, o conjunto das relações sociais. Conservação inalterada do velho modo de produção foi, ao contrário, a condição primeira de existência de todas as classes industriais anteriores. 0 revolucionamento contínuo da produção, o abalo ininterrupto de todas as situações sociais, a insegurança e a movimentação eternas distinguem a época burguesa de todas as outras (MARX, 1998, p. 43).

Em sua existência como corporificação do capital, a máquina, vista como produto ou como processo industrial, transforma a ciência em uma força produtiva dominada pelos capitalistas:

0 desenvolvimento do meio de trabalho em maquinaria não é casual para o capital, mas é a reconfiguração do meio de trabalho tradicionalmente herdado em uma forma adequada ao capital. A acumulação do saber e da habilidade, das forças produtivas gerais do cérebro social, é desse modo absorvida no capital em oposição ao trabalho, e aparece consequentemente como qualidade do capital, mais precisamente do capital fixo, na medida em que ele ingressa como meio de produção propriamente dito no processo de produção. A maquinaria aparece, portanto, como a forma mais adequada do capital fixo, e o capital fixo, na medida em que o capital é considerado na relação consigo mesmo, como a forma mais adequada do capital de modo geral (MARX, 2011, p. 581-582).

Desta forma, mesmo sendo o acúmulo de séculos do trabalho de cientistas, que, em muitos casos se converteram em proletários assalariados, ela se apresenta como alheia aos trabalhadores, levando à mistificação do capital, à máxima fetichização da mercadoria:

A ciência, que força os membros inanimados da maquinaria a agirem adequadamente como autômatos por sua construção, não existe na consciência do trabalhador, mas atua sobre ele por meio da máquina como poder estranho, como poder da própria máquina (MARX, 2011, p. 580-581).

Esse processo de estranhamento dos trabalhadores com relação à sua própria produção, à medida que seu corpo foi sendo objetivado nas três partes que, segundo Marx, constituem o sistema de máquinas: máquina- 
ferramenta, motor e mecanismos de transmissão e controle, ocorreu (e ocorre) em um longo período histórico de sucessivas ondas de incorporação tecnológica à produção, a revolução industrial.

Segundo Bevilaqua (2015), a primeira fase da revolução industrial, entre 1735 e 1840, foi dinamizada pelo surgimento das máquinasferramentas. Uma segunda fase desta, entre 1848 e 1945, ao incorporar novas fontes de energia térmica à produção, é responsável pela expansão deste modo de produção por todo o globo. No pós-guerra, a terceira fase da Revolução Industrial completa a objetificação do corpo do trabalhador na maquinaria, plasmando neste sistema funções que eram então exclusivas do cérebro humano, como a transmissão de informações e o controle, através da informática. A possibilidade de generalização da automação da produção aberta por esse processo enseja um novo tipo de crise, distinta das crises clássicas de superprodução, a crise da erosão do tempo de trabalho como paradigma de mensuração de valor, à medida que a ciência se torna a principal força produtiva social.

\section{A revolução científico-técnica, a terceira fase da Revolução Industrial}

Um século e meio após os estudos históricos de Marx e Engels, podemos perceber que se a primeira fase da Revolução Industrial, entre 1735 e 1840, é a parteira de um novo modo de produção, e uma segunda fase desta, entre 1848 e 19451, ao incorporar novas fontes de energia térmica à produção, é responsável pela expansão do sistema capitalista por todo o globo, sua terceira fase, iniciada no pós-guerra, e da qual somos contemporâneos, com a revolução dos mecanismos de transmissão e controle, a cibernética, ao permitir a automação da produção, leva o sistema capitalista a uma crise que se apresenta insuperável dentro dos marcos do sistema (BEVILAQUA, 2015).

Se não podemos responsabilizar diretamente a produção científica, entendida em seu sentido mais estreito como corpo de conhecimento sistematizado e promovido a partir de instituições oficiais (universidades, periódicos, conferências etc.), pelo impulso inicial que levou à 
industrialização ${ }^{3}$, também não podemos descartar o poder explicativo neste contexto de um uso mais abrangente do termo ciência, considerado como uma nova atitude paradigmática frente à realidade material, experimentação empírica e autoridade da hierarquia religiosa.

Entretanto, com o tempo, essa distinção vai sendo apagada e o desenvolvimento da técnica não é mais um resultado de avanços pragmáticos e empíricos na maneira de produzir. A ciência assumiu o papel de dirigente do desenvolvimento tecnológico, os ramos de produção se convertem em campos de atividades criados e controlados por ela. A ciência se converte em uma força produtiva direta (SANTOS, 1983, p. 9).

A economia passa a direcionar de forma mais contundente o conjunto da pesquisa científica, gigantescos ramos da indústria que não existiam são criados a partir de descobertas científicas e passam a atrair para si, em uma espécie de ciclo virtuoso, mais trabalho de pesquisa, como exemplificam o caso da indústria química, da aviação, da informática, entre outros. 0 trabalho científico sai da periferia e se coloca no centro do processo produtivo, como sua força mais importante.

Santos (1983) notou que a produção científica se tornou parte essencial da acumulação. Os custos em pesquisa e desenvolvimento são parte do custo final do produto e os laboratórios e centros de pesquisa se transferem para dentro das empresas. A atividade científica é agora vista como um investimento que se incorpora ao capital constante e à variável: entra nos custos de produção (p. 61-62).

\footnotetext{
${ }^{3}$ Marx, nos Grundrisse, antecipa a conclusão que historiadores econômicos levaram mais de um século para assentar, de que "o desenvolvimento da maquinaria por essa via [aplicação sistemática da ciência] só ocorre quando a grande indústria já atingiu um estágio mais elevado e o conjunto das ciências já se encontra cativo a serviço do capital", ou seja, "esta não é a via que deu origem à maquinaria no geral, e menos ainda a via pela qual ela avança em particular". A via original de desenvolvimento do sistema de máquinas para Marx "é a análise - pela divisão do trabalho, que transforma as operações dos trabalhadores cada vez mais em operações mecânicas, de tal modo que a certa altura o mecanismo pode ocupar os seus lugares" (MARX, 2011, p. 587). A construção das primeiras máquinas é consequência da especialização do trabalho artesanal, uma característica da manufatura medieval, pois "é justamente porque a habilidade artesanal permanece como a base do processo de produção que cada trabalhador passa a dedicar-se exclusivamente a uma função parcial, e sua força de trabalho é então transformada em órgão vitalício dessa função parcial" (MARX, 1996, l. 1, v. 1, p. 455).
} 
Este autor propõe uma ampliação do esquema original D-M-D de Marx, que, ao incorporar a atividade científica, pode ser reescrito da seguinte forma:

$$
\begin{array}{ccc} 
& \mathrm{CI} \ldots \mathrm{I} \_ \\
\mathrm{D}-\mathrm{M} & \\
& \mathrm{CP} \ldots \ldots \mathrm{M}^{\prime}-\mathrm{D}-\mathrm{M}^{\prime}-\mathrm{CPI} \ldots \mathrm{MI}-\mathrm{DI}
\end{array}
$$

Na qual CI é o capital investido em tecnologia, o que permite que um capital, acumulado anteriormente, torne-se CPI, ou capital investido em um novo produto, resultado da pesquisa realizada (SANTOS, 1983, p. 76-81).

Por sua vez, a ciência se converte em tecnociência, que para ser realizada requer, cada vez mais, a invocação de uma parcela gigantesca de trabalho acumulado na forma de laboratórios, instrumentos científicos e capital humano (trabalho pretérito em educação e formação). A partir deste ponto não bastam mais bons mecânicos, inventores, artesãos, autodidatas, homens e mulheres práticos, esses personagens que protagonizaram o desenvolvimento tecnológico na época da manufatura e nos primórdios da indústria.

O processo empírico, baseado na tentativa e erro, adquire um novo significado dentro do contexto da produção científica industrial. Em seu diário, Thomas Edison relata ter testado 1.600 diferentes fibras até chegar no carbono e posteriormente no tungstênio como materiais ideias para a fabricação do filamento de suas lâmpadas. Mas, não se pode tomar essa anotação como evidência de que ele fez tudo isso sozinho, sua empresa contava com dezenas de pesquisadores trabalhando em tempo integral no desenvolvimento de seus produtos.

Talvez Edison seja o melhor arquétipo desta transição, com a qual a produção científica passou a ser quantificada pelo número de patentes registradas. Mesmo que o sistema de patentes já existisse há séculos, e que já tivessem ocorridas ferozes disputas legais em torno dessas, como a experimentada por James Watt que patenteou o motor a vapor em 1796, 
Edison acumulou 1.093 patentes em seu nome, apenas nos Estados Unidos, e utilizou-se destas para se ascender à classe burguesa.

Santos (1983) nos mostra como, no pós-guerra, esse processo de entrelaçamento entre a ciência e o capital se estreita ainda mais. Em seu artigo Mudança Tecnológica e Economia Mundial, apresentado aos seus alunos, mas ainda não publicado, este autor chama atenção para o fato de que:

A questão da integração da ciência como força produtiva é parte indispensável do processo de produção, pode ser medida através da intensidade dos gastos com pesquisa e desenvolvimento em relação ao produto de cada setor econômico (SANTOS, 2002, manuscritos).

Neste texto, Santos apresenta os dados do informe sobre ciência e tecnologia da OECD colhidos em fins década de 1980 e, com base neles, demonstra como estes investimentos cresceram maciçamente depois da Segunda Guerra Mundial. Para se ter uma ideia de como essa tendência continuou evoluindo, em 2016 o total mundial desses gastos foi de cerca de 1,15 trilhão de dólares, ou seja, mais de $2 \%$ do PIB mundial. Estão aí englobados os gastos com pesquisa básica, aplicada e em desenvolvimento (ou seja, inovações baseadas em tecnologia já existente).

Cada vez mais, as pesquisas de ponta em diversas áreas dependem de projetos multibilionários, todos eles com forte participação estatal. 0 Grande Colisor de Hádrons levou uma década para ser construído e consumiu 7,5 bilhões de euros até 2010. 0 orçamento anual para sua operação consome cerca de 1 bilhão de dólares por ano. 0 Observatório de Ondas Gravitacionais por Interferômetro Laser, que permitiu a observação de ondas gravitacionais custou 1,1 bilhão de dólares em 40 anos. No Projeto Genoma Humano foram dispendidos, até o sequenciamento concluído em 2003, 2,7 bilhões de dólares. São pesquisas que envolvem ciência básica, mas que também levaram ao desenvolvimento de diversas tecnologias para se viabilizarem, e resultam na criação de diversos novos produtos.

Nenhum destes projetos citados acima custou tanto quanto a Estação Espacial Internacional, cerca de 150 bilhões de dólares até 2015, divididos entre Estados Unidos, Rússia, Japão, Canadá e a Agência Espacial Europeia, 
composta por 13 países deste continente, quase $50 \%$ a mais que o projeto Apollo, que custou 23 bilhões de dólares em 1973, o que equivale a 107 bilhões de dólares se atualizarmos o valor para o parâmetro de 2016.

Podemos considerar como precursor desses megaprojetos de produção científica em escala industrial, o projeto Manhattan, que permitiu o controle sobre a fissão nuclear no final da Segunda Guerra, ao custo de 2 bilhões de dólares de então, o que hoje equivaleria a mais de 22 bilhões de dólares. A maioria destes projetos está ligada diretamente à área militar, sendo que o Manhattan foi desenvolvido no curso da Segunda Guerra, e permitiu a construção da bomba atômica, o que comprova o importante papel que este conflito e, posteriormente a corrida armamentista da guerra fria, desempenharam no crescimento dos investimentos em ciência.

Todos esses projetos foram financiados principalmente com recursos públicos e envolveram centenas, ou mesmo milhares, de pesquisadores trabalhando conjuntamente. Mas, a principal destinação dos investimentos foi em obras de infraestrutura, compra de equipamentos, gastos administrativos, entre outros custos indiretos.

O projeto Manhattan, por exemplo, chegou a empregar cerca de $130 \mathrm{mil}$ pessoas, a maioria delas operários da construção civil, mas, neste e nos demais megaprojetos, foram significativas as contratações de trabalhadores especializados e qualificados, principalmente na produção dos equipamentos.

Na segunda metade do século XX, os gastos do setor privado com ciência e tecnologia seguiram o mesmo caminho de crescimento acelerado do investimento público, ainda que mais voltados para a pesquisa aplicada e para a inovação, onde o retorno é mais imediato.

A estruturação dos centros de pesquisa e design dentro das grandes empresas começa no início do século XX, o que permite que esses assumam parte de um espaço que era até então exclusivo das universidades. Em 1925, com a emergência da telefonia como um negócio mundial, quatro mil cientistas e engenheiros foram contratados pelo recém-criado Bell Telephone Laboratories. Ao longo de sua história, esta instituição privada, mas que 
sempre recebeu bolsas da DARPA, agência de pesquisa em defesa dos EUA, hospedou 8 trabalhos que receberam o Nobel, além de ter sido lá que revolucionárias tecnologias foram desenvolvidas, como o transistor, o laser, o sistema operacional Unix e a linguagem de programação C. Desde 2016 este centro de pesquisa é de propriedade da gigante de telecomunicações finlandesa Nokia.

A participação da empresa Celera no Projeto do Genoma Humano e mais recentemente as mudanças relacionadas à indústria espacial nos Estados Unidos, com a NASA passando a conviver com outras fabricantes de foguetes, como a Space X e a Blue Origin, demonstram o controle cada vez mais direto do setor privado sobre essas áreas estratégicas.

\subsection{Automação e inteligência artificial}

A divisão proposta por Bevilaqua da Revolução Industrial em três fases, derivadas da análise de Marx dos três mecanismos que compõem o sistema de máquinas, admite a existência de sobreposições temporais, como a invenção de Joseph-Marie Jacquard, um pioneiro da automação que construiu, ainda em 1801, um tear programável através de cartões perfurados. Este trabalho é fundamental para a posterior criação dos computadores, da mesma forma que os trabalhos teóricos sobre as máquinas analíticas e algoritmos por Charles Babbage e Ada Lovelace, realizados ainda no século XIX (BEVILAQUA, 2015, p. 277-278).

0 fato dos primeiros computadores comercializados terem sido construídos no final da Segunda Guerra Mundial, com base na solução proposta por Alan Turing ao "problema da decisão, Entscheidungsproblem, proposto por David Hilbert como um desafio em 1928”, é uma demonstração de como "diferentes ideias e inovações podem ser articuladas mesmo com séculos de distância entre elas e que nem toda invenção resulta imediatamente em uma inovação, e que sua difusão, revelando seu potencial, pode ocorrer muito tempo depois de seu primeiro uso" (BEVILAQUA, 2015, p. 277). 
Independentemente de ser o acúmulo de trabalho de milhares de anos de desenvolvimento técnico, que pode ser remontado ao mecanismo de Anticítera ${ }^{4}$, primeiro computador analógico de que se tem notícia, construído há mais de 2 mil anos, é só na terceira fase da Revolução Industrial, iniciada no pós-guerra, que a adoção de máquinas programáveis para exercer atividades de transmissão e controle revolucionam todo o processo produtivo.

Santos (1983) observa como o custo dos microchips sofre uma redução a partir da década de 50 e como seu uso inicialmente se expande pelo setor de serviços e gestão (p. 40-41). A partir daí eles se tornam ubíquos: na agricultura, na indústria, nos serviços, no sistema financeiro, na educação, na produção cultural, não existe departamento ou ramo da produção que não foi revolucionado pelo uso de computadores.

Ao assumirem as tarefas mais mecânicas controladas anteriormente pelo cérebro humano, através de uma estratégia reducionista de dividir o problema cognitivo em pequenas tarefas, os computadores, vistos como unidade dialética entre hardware e software, permitiram que diversas novas atividades fossem automatizadas.

Este processo pôde ser antevisto por Marx, pois ainda que em sua época não houvesse mecanismos programáveis de controle, já havia uma sofisticação bastante grande nos mecanismos de transmissão, como correias, polias etc. Nas minas alemãs, séculos antes de Marx, sistemas articulados de hastes de madeira chamados de Stangenkunsten transmitiam energia mecânica, obtida de geradores hidráulicos, para bombas, foles, e elevadores que transportavam os mineiros, nas montanhas, a quilômetros de distância dos vales dos rios.

\footnotetext{
${ }^{4}$ Descoberto por mergulhadores em 1901 nos restos naufragados de um navio nas costas da ilha grega de Anticítera, esse computador analógico, com 37 engrenagens, despertou os interesses dos historiadores desde a segunda metade do século XX e sua recente reconstrução a partir de modernas tomografias computadorizadas mostrou que os antigos gregos tinham um conhecimento mais avançado de mecânica do que se supunha. Já era conhecida uma menção de Plínio o Velho a este objeto, mas até então acreditava-se que se tratava de uma descrição exagerada.
} 
Isso levou Marx a entender o sistema automático de máquinas, no sentido de que

automático é apenas a sua forma mais adequada, mais aperfeiçoada, e somente o que transforma a própria maquinaria em um sistema, posto em movimento por um autômato, por uma força motriz que se movimenta por si mesma; tal autômato consistindo em numerosos órgãos mecânicos e intelectuais, de modo que os próprios trabalhadores são definidos somente como membros conscientes dele (MARX, 2011, p. 929).

Essa é uma diferença muito significativa com o papel que a ferramenta historicamente desempenhou como meio de trabalho, algo interposto entre o trabalhador e seu objeto de trabalho. As ferramentas são incorporadas pelo cérebro humano na representação mental que ele faz do nosso corpo. Por isso nós somos capazes de uma perícia tão grande ao manuseá-las, como se o nosso tato se estendesse para além da nossa pele e abarcasse a ferramenta, seja ela uma chave de fenda, uma bengala, um pincel ou o volante de um automóvel. Contrastando, em nenhum sentido a máquina aparece como meio de trabalho do trabalhador individual. A sua differentia specifica não é de forma alguma, como no meio de trabalho, a de mediar a atividade do trabalhador sobre o objeto; ao contrário, esta atividade é posta de tal modo que tão somente medeia o trabalho da máquina, a sua ação sobre a matériaprima - supervisionando-a e mantendo-a livre de falhas (MARX, 2011, p. 929930).

Dessa perda de controle por parte do trabalhador direto decorre o estranhamento do qual escritores e cineastas se nutriram para construir um cenário no qual os humanos são desalojados por robôs, desde o Frankenstein de Mary Shelley ${ }^{5}$. Marx nota que:

Não é como no instrumento, que o trabalhador anima como um órgão com a sua própria habilidade e atividade e cujo manejo, em consequência, dependia de sua virtuosidade. Ao contrário, a própria máquina, que para o trabalhador possui destreza e força, é o virtuose que possui sua própria alma nas leis mecânicas que nela atuam e que para seu contínuo automovimento consome carvão, óleo etc. (matérias instrumentais), da mesma maneira que o trabalhador consome alimentos (MARX, 2011, p. 930).

\footnotetext{
${ }^{5}$ O Frankstein de Shelley, no qual uma criação humana se revolta e ataca seus criadores é um tema recorrente na cultura de massas contemporânea. Podemos citar exemplos como o de Blade Runner, 2001 - Uma odisseia no espaço, Exterminador do Futuro entre outros.
} 
Vivenciamos no presente uma confirmação dessa projeção de Marx, com o acelerado desenvolvimento da inteligência artificial baseado em redes neurais, nos quais os sistemas aprendem ao considerarem uma série de exemplos, sendo capazes de tomar decisões sem que tenham sido programados para qualquer tarefa específica.

Os pioneiros das ciências da computação já haviam teorizado acerca das redes neurais ainda nos anos 40 e a Universidade de Stanford chegou a implementar uma rede neural funcional nos anos 60, ligando memistors ${ }^{6} \mathrm{em}$ rede, chamada ADALINE, e que foi usada na prática para reduzir ecos em ligações telefônicas.

Contudo, a tecnologia enfrentou barreiras e o desenvolvimento da arquitetura de Von Neumann concentrou todas as atenções e financiamentos, convertendo-se no paradigma dominante, sendo-o até hoje.

Durante décadas, as redes neurais se mantiveram apenas como construções teóricas, de interesse acadêmico, com pouca aplicação prática. Mas, nos anos 80 foram disseminados os sistemas especialistas, uma das primeiras formas bem-sucedidas de uso de software de inteligência artificial. Eram programas que auxiliavam na realização de diagnósticos, no gerenciamento de riscos, mas também na área militar, como na detecção de submarinos.

Um novo salto ocorreu nas primeiras décadas do século XXI e os softwares de inteligência artificial se disseminaram rapidamente por toda a sociedade. Assumiram o comando de carros, aviões, trens e grandes embarcações. Recomendam livros, filmes e produtos com base no histórico pretérito de consumo. Reconhecem a voz, a face, as digitais e até o padrão de respiração das pessoas.

A IBM criou a plataforma Watson, que foi lançada como prova de conceito ao diversas aplicações, entre elas diagnósticos oncológicos, análise de investimentos, previsão do tempo etc. O Google lançou o Alpha Go, que em

${ }^{6}$ Componente eletrônico que se assemelha a um resistor, mas com memória e a possibilidade de realizar operações lógicas. Considerável como possível próximo paradigma em tecnologia de armazenamento. 
março de 2016 venceu um match contra Lee Sedol, dezoito vezes campeão mundial deste jogo extremamente popular na Ásia e que muitos consideravam um campo no qual as máquinas ainda levariam décadas para vencer os seres humanos, por conta do tamanho de seu tabuleiro, que comporta $2 \times 10^{170}$ posições, 1 milhão de trilhões de trilhões de trilhões de trilhões de vezes as posições possíveis em uma partida de xadrez. A segunda fase deste projeto, anunciada em dezembro de 2017, chama-se Alpha Zero, um software capaz de vencer qualquer outro humano, ou outro software criado até o momento, em diferentes jogos, que ele aprende jogando milhares de partidas contra si mesmo.

Ainda que somente agora o debate sobre os impactos da automação se generalizou para sociedade como um todo, os efeitos deste processo vêm sendo estudados desde o pós-guerra. Santos (1983) refere-se ao trabalho de Radovan Richta, que promoveu um fértil debate no interior do campo socialista acerca do salto tecnológico ocorrido no pós-guerra. Este autor relaciona as transformações que testemunhava à tendência apontada nos Grundrisse da conversão da ciência na principal força do processo produtivo. Para este autor, esta nova configuração das forças produtivas não poderia ser contida dentro das relações sociais capitalistas, ou mesmo socialistas, requerendo para seu desenvolvimento relações novas, superiores, comunistas.

Para Richta a "Revolução Científico-Técnica seria responsável por eliminar o trabalho elementar, substituindo-o pelo trabalho científico, que no núcleo da produção e da vida social, torna o desenvolvimento humano um fim em si mesmo. Esta tendência ao general intelect não está, contudo, concretizada em absoluto, mas já aparece como potência” (BEVILAQUA, 2015 , p. 290). 


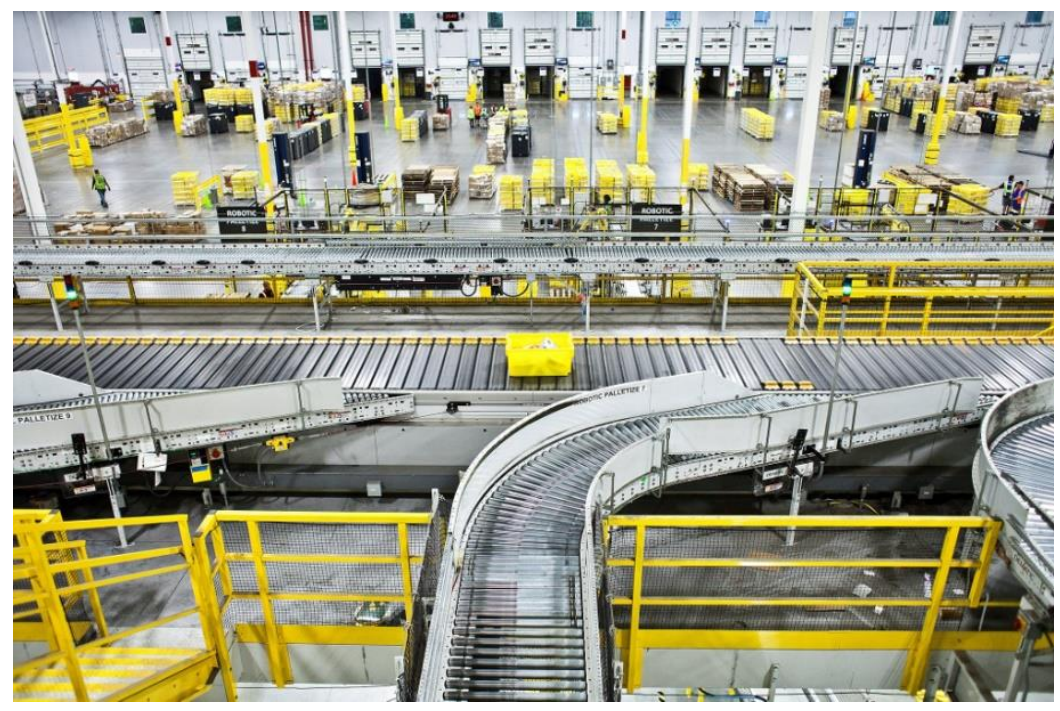

Figura 1: Centro de distribuição automatizado da Amazon. Fonte: The New York Times

0 fato dessa tendência aparecer como potência não determina mecanicamente que ela se absolutizará, ainda mais quando sua afirmação implica, ao final, o agravamento da crise orgânica do capital. Muitas das tecnologias que hoje aparecem como inovadoras, como o carro elétrico, os drones, as redes neurais, existem há décadas. Santos (1983), mostra como os monopólios retardam ao máximo a automação. Bevilaqua nota que a contradição desta fase de decomposição do sistema capitalista, na qual o desenvolvimento das forças produtivas é restringido pela crise do valor, pode ser constatada quando se observa que um operário de uma indústria de composição orgânica média, carrega em seu bolso um smartphone que incorpora mais tecnologia do que as máquinas na qual ele trabalha para seu sustento. A única explicação possível para tal fenômeno é a ação dos grandes monopólios que buscam desesperadamente retardar a adoção da automação, em uma tentativa de prolongar a vigência da lei do valor. Contudo, não conseguem reter esse movimento, dada a impossibilidade de um único monopólio dominar todo o mercado mundial, mas também, de forma cada vez mais acentuada, pela emergência da China, que se converteu nas últimas décadas na fábrica do mundo, investindo maciçamente em automação, o que renova a competição entre os sistemas (BEVILAQUA, 2015, p. 271). 
O forte impacto dessas tecnologias na redução dos gastos com capital variável leva a uma corrida tecnológica entre as grandes empresas, que fica evidente quando comparamos a lista das empresas que mais investiram em pesquisa e desenvolvimento em 2011 e 2017, segundo um estudo da

\section{PricewaterhouseCoopers.}

Esta lista contém algumas omissões importantes, como o caso da gigante chinesa Huawei, que deveria estar na oitava posição com investimento de 11,2 bilhões de dólares, superior ao da Apple. Mas ela nos serve para ilustrar o rápido ritmo de substituição tecnológica.

\begin{tabular}{|c|c|c|c|c|c|}
\hline 2017 Rank & $\begin{array}{l}\text { Company } \\
\text { Name }\end{array}$ & Country & $\begin{array}{l}\text { Primary } \\
\text { Industry }\end{array}$ & 2011 & 2017 \\
\hline 1 & $\begin{array}{l}\text { Amazon.com, } \\
\text { Inc. }\end{array}$ & United States & $\begin{array}{l}\text { Intemet and } \\
\text { Direct } \\
\text { Marketing } \\
\text { Retail } \\
\text { Internet }\end{array}$ & 1,73 & 16,09 \\
\hline 2 & Aphabet Inc. & United States & $\begin{array}{l}\text { Software and } \\
\text { Services }\end{array}$ & 3.76 & 13,95 \\
\hline 3 & $\begin{array}{c}\text { Intel } \\
\text { Corporation }\end{array}$ & United States & $\begin{array}{l}\text { Semiconducto } \\
\text { rs }\end{array}$ & 6,58 & 12,74 \\
\hline 4 & $\begin{array}{c}\text { Samsung } \\
\text { Electronics } \\
\text { Co. Ltd. }\end{array}$ & South Korea & $\begin{array}{l}\text { Technology } \\
\text { Hardware, } \\
\text { Storage and } \\
\text { Peripherals }\end{array}$ & 7.72 & 12,72 \\
\hline 5 & $\begin{array}{c}\text { volkswagen } \\
\text { Aktiengesellsc } \\
\text { haft }\end{array}$ & Germany & $\begin{array}{l}\text { Automobile } \\
\text { Manufacturers }\end{array}$ & 7,25 & 12,15 \\
\hline 6 & $\begin{array}{l}\text { Microsoft } \\
\text { Corporation }\end{array}$ & United States & $\begin{array}{l}\text { Systems } \\
\text { Software }\end{array}$ & 8,71 & 11,99 \\
\hline 7 & $\begin{array}{c}\text { Roche Holding } \\
\text { AG }\end{array}$ & Switzerland & $\begin{array}{c}\text { Pharmaceutic } \\
\text { als }\end{array}$ & 9,87 & 11,35 \\
\hline 8 & $\begin{array}{l}\text { Merck \& Co.. } \\
\text { Inc. }\end{array}$ & United States & $\begin{array}{l}\text { Pharmaceutic } \\
\text { als }\end{array}$ & 10,99 & 10,12 \\
\hline 9 & Apple Inc. & United States & $\begin{array}{l}\text { Technology } \\
\text { Hardware, } \\
\text { Storage and } \\
\text { Peripherals }\end{array}$ & 1,78 & 10,05 \\
\hline 10 & Novartis $A G$ & Switzerland & 'harmaceuticals & 9,07 & 9,57 \\
\hline 11 & $\begin{array}{l}\text { Toyota Motor } \\
\text { Corporation }\end{array}$ & Japan & $\begin{array}{l}\text { Automobile } \\
\text { Manufacturers }\end{array}$ & 6,55 & 9,31 \\
\hline 12 & $\begin{array}{l}\text { Johns on \& } \\
\text { Johnson }\end{array}$ & United States & $\begin{array}{c}\text { Pharmaceutic } \\
\text { als }\end{array}$ & 6,84 & 9,10 \\
\hline 13 & $\begin{array}{l}\text { General } \\
\text { Motors } \\
\text { Company }\end{array}$ & United States & $\begin{array}{l}\text { Automobile } \\
\text { Manufacturers }\end{array}$ & 0,00 & 8,10 \\
\hline 14 & Pfizer Inc. & United States & $\begin{array}{c}\text { Pharmaceutic } \\
\text { als }\end{array}$ & 9,39 & 7,87 \\
\hline 15 & $\begin{array}{l}\text { Ford Motor } \\
\text { Company }\end{array}$ & United States & $\begin{array}{l}\text { Automobile } \\
\text { Manufacturers }\end{array}$ & 5,00 & 7,30 \\
\hline 16 & DaimlerAG & Germany & $\begin{array}{l}\text { Automobile } \\
\text { Manufacturers }\end{array}$ & 4,43 & 6,86 \\
\hline 17 & $\begin{array}{c}\text { Oracle } \\
\text { Corporation }\end{array}$ & United States & $\begin{array}{l}\text { Systems } \\
\text { Software }\end{array}$ & 4,52 & 6,82 \\
\hline 18 & $\begin{array}{c}\text { Cisco } \\
\text { Systems, Inc. }\end{array}$ & United States & $\begin{array}{l}\text { Communicatio } \\
\text { ns Equipment }\end{array}$ & 5,27 & 6,30 \\
\hline 19 & $\begin{array}{l}\text { Honda Motor } \\
\text { Co., Ltd. }\end{array}$ & Japan & $\begin{array}{l}\text { Automobile } \\
\text { Manufacturers }\end{array}$ & 4,37 & 6.20 \\
\hline 20 & Facebook, Inc. & . United States & $\begin{array}{l}\text { Internet } \\
\text { Software and } \\
\text { Services }\end{array}$ & 0,14 & 5,92 \\
\hline
\end{tabular}

Figura 2: Investimento em pesquisa e desenvolvimento pelas grandes corporações. Fonte: Pricewaterhouse Coopers. 
Nestes seis anos, a Amazon, que aumentou seu investimento em P\&D em $830 \%$ e a Alphabet (nome da holding criada pela Google), que o fez em 271\%, são duas grandes investidoras em inteligência artificial. A Amazon cresceu a partir de uma livraria online para um gigantesco comércio em geral (logística) e depois para uma megaholding que comprou diversas empresas de alta tecnologia, vendendo serviços 'na nuvem'. Nos seus depósitos operam mais de 100 mil robôs, que complementam o trabalho das 125 mil pessoas que recebem os pedidos de compras, os separam, conferem, embalam e enviam.

0 crescimento de $67 \%$ nos gastos com pesquisa e design da Volkswagen em 5 anos refere-se aos investimentos nos carros elétricos, mas também se insere nos esforços do Ministério da Educação e Pesquisa da República Federativa da Alemanha que criou um programa chamado Projeto Indústria do Futuro 4.0 (Zukunftsprojekt Industrie 4.0), no qual propõe, a partir da interação entre sistemas ciberfísicos, a criação da fábrica inteligente.

Dois rápidos exemplos e um dado nos mostram o nível de contradição que a atual onda de automação abre para um sistema que acumula riquezas, e poder político sobre a exploração do tempo de trabalho:

Em 1979, a General Motors empregava mais de 800 mil funcionários, e tinha receita de uns 11 bilhões de dólares. Em 2012, Google tinha receita de uns 40 bilhões de dólares, enquanto empregava 58 mil pessoas. [...] No seu auge, em 2004, a Blockbuster tinha 84 mil funcionários, e tinha receitas de 6 bilhões de dólares. Em 2016, a Netflix tinha 4500 funcionários, e teve receita de 9 bilhões de dólares. [...] Em 1998, empregados dos EUA trabalharam um total de 194 bilhões de horas. Ao longo dos 15 anos seguintes, o produto aumentou em $42 \%$, mas em 2013, o total de horas trabalhadas por empregados dos EUA ainda era 194 bilhões de horas (KURZGESAGT. 2017).

Os sistemas automáticos de máquinas de novo tipo, baseados na inteligência artificial, estão sendo rapidamente adotados em todos os ramos da economia, inclusive no setor de serviços, que era visto como o baluarte dos empregos após a automação das fábricas. Médicos, arquitetos, músicos, professores, não existe profissão que estará alheia a esses impactos. 


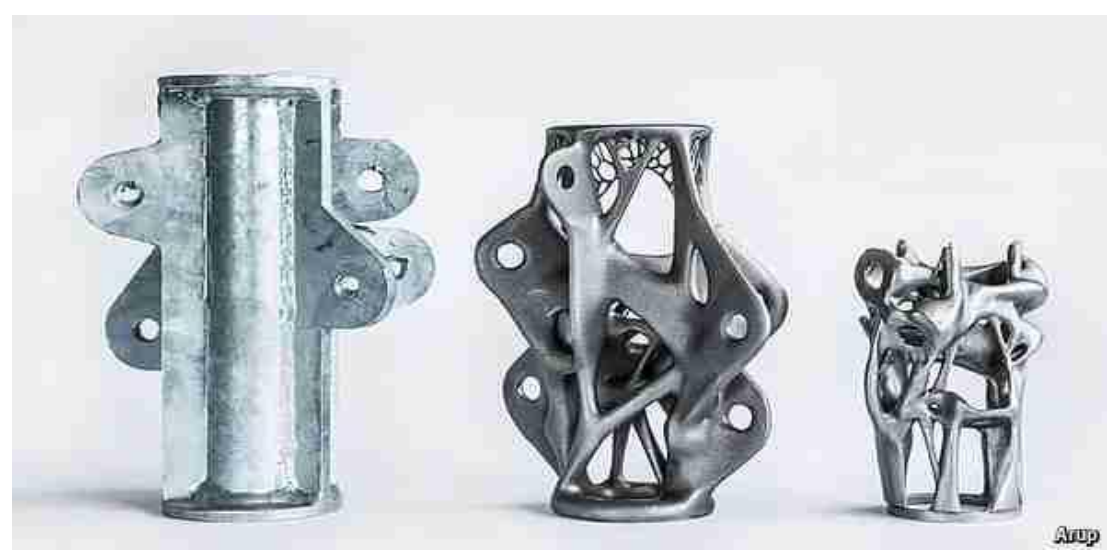

Figura 3: Design evolutivo com inteligência artificial. Fonte: Site da ARUP, empresa britânica que desenvolve processos de design baseados em inteligência artificial

Nesta figura podemos ver um trabalho realizado como um projeto de pesquisa por uma empresa afirma global de engenheiros consultores, chamada Arup. 0 mais da esquerda é uma peça usada normalmente para fixar cabos. As outras duas componentes resultam da análise de um computador para encontrar o design ideal, capaz de fornecer a mesma força, mas usando menos material. 0 componente do meio foi otimizado mantendo-se os braços e cabos no mesmo local e resultou em uma economia de peso de $40 \%$. A terceira versão foi obtida permitindo que o sistema reconectasse completamente toda a estrutura, o que levou a uma economia de peso de $75 \%$.

É difícil antevermos qual será o impacto dessas tecnologias dentro de algumas décadas. E ainda mais, qual o significado destas para o desenvolvimento da luta de classes? Bevilaqua chama atenção para a contradição representada pela automação, que se por um lado atende uma necessidade econômica dos capitalistas, por outro afirma a autonegação do capital:

O grande impulso no desenvolvimento dessas máquinas ocorre já sob a sombra da crise orgânica do capital, mas, a primeira arma que ela municia ao capital, a automação, que se traduz num aumento de produtividade sem paralelo representa também a incidência do limite absoluto da relação capital, que se nega, ao tornar impossível a possibilidade de se mensurar o 
valor da ciência, como força produtiva, pelo tempo de trabalho (BEVILAQUA, 2015, p. 271).

Como vimos, a história do capitalismo é a história da Revolução Industrial. Esta, por sua vez estabelece uma complexa dialética entre ciência e tecnologia, ao ocorrer a "síntese entre o desenvolvimento do sistema produtivo e o desenvolvimento do conhecimento humano sistemático" (SANTOS, 1983, p.13).

Sobre a conversão do trabalho científico em força produtiva, Marx afirma nos Grundrisse:

A natureza não constrói máquinas, nem locomotivas, estradas de ferro, telégrafos elétricos, selfacting mules etc. São estes produtos da indústria humana; material natural, transformado em órgãos da vontade humana sobre a natureza ou de sua atuação na natureza, são órgãos do cérebro humano criados pela mão humana; força objetiva do conhecimento. 0 desenvolvimento do capital fixo revela até que ponto o conhecimento ou knowledge social geral, se converteu em força produtiva imediata e, portanto, até que ponto as condições do processo de vida social mesmo, entraram sob o controle do general intellect e remodeladas conforme o mesmo. Até que ponto as forças produtivas sociais são produzidas não somente na forma do conhecimento, mas como órgãos imediatos da prática social, do processo vital real. (MARX, 2009, v. 2, p. 229-230).

Imbuída da lógica da relação capital, a intensificação da produção científica, que resulta no desenvolvimento de novas tecnologias, é vista como forma de reduzir custos, principalmente com o capital variável. Quanto "maior a especulação quanto ao valor de seus produtos, o superlucro do qual participa abandona a esfera do trabalho por tempo, embora seja esta medida a que toma para estabelecer seu preço especulativo". A ciência, assim como a educação, embora possa ser objeto de produção de mais-valia, nunca poderá ter seu verdadeiro valor mensurado em tempo social, posto que incorpora um tempo histórico incomensurável na formação do intelecto geral e no desenvolvimento do conhecimento social geral da humanidade, com suas 
continuidades, descontinuidades, rupturas, saltos e regressões. (BEVILAQUA, 2015, p. 404).

Como pode o capital mensurar esse trabalho se:

0 produto do trabalho intelectual - a ciência - é sempre muito inferior a seu valor, porque o tempo de trabalho necessário para sua reprodução não guarda proporção alguma com o [trabalho] exigido para sua criação original. Por exemplo, qualquer jovem no colégio pode aprender em uma hora a teoria dos binômios (MARX, 1980, v.1, p. 327, tradução nossa)

Essa crise se generaliza para todos os aspectos da sociedade ao incidir sobre a lei geral da acumulação capitalista, que condensa em si as diversas contradições da relação-capital, determinando a própria lei populacional deste modo de produção.

Existem diversas formas através das quais essa generalização se dá, no caso da produção científica é patente uma violação da lei do valor através do crescimento exponencial de publicações que trazem resultados cada vez mais inverificáveis e apartados da realidade.

Porém, mais do que apenas uma crise da produção científica, a Crise na Ciência, exige, para se ter com uma compreensão mais elaborada desse fenômeno, que nos ocupemos dos paradigmas internos dos diferentes campos científicos e como estes se conectam aos paradigmas mais gerais da sociedade, que estão mais diretamente ligados à lógica imposta pela relação-capital.

\section{Referências}

BEVILAQUA, A. P. A Crise do Capital em Marx e suas Implicações nos

Paradigmas da Educação: Contribuição ao Repensar Pedagógico no Século XXI. Fortaleza: Inverta/ UFC, 2011.

BEVILAQUA, A. P. A Crise Orgânica do Capital: o Valor, a Ciência e a Educação. 2015. Tese (Doutorado em Educação Brasileira) - Faculdade de Educação (FACED), Universidade Federal do Ceará, Fortaleza.

BEVILAQUA, A. P. A Crise Orgânica do Capital: o Valor, a Ciência e a Educação. Vol. 1. Rio de Janeiro: Inverta, 2017. 
ENGELS. F. The Part Played by Labour in the Transition from Ape to Man. In Karl Marx and Frederick Engels Collected Works: Volume 25, London, UK: Lawrence \& Wishart, 2010A, pp. 452-465.

ENGELS. F. The Origin of the Family, Private Property and the State. In Karl Marx and Frederick Engels Collected Works: Volume 26, London, UK: Lawrence \& Wishart, 2010B, pp. 129-276.

ENGELS. F. The Condition of the Working-Class in England. In Karl Marx and Frederick Engels Collected Works: Volume 04, London, UK: Lawrence \& Wishart, 2010C, pp. 295-553.

ENGELS. F. A Origem da Família, da Propriedade Privada e do Estado. Rio de Janeiro: Editorial Vitória, 1964.

ENGELS. F. A situação da classe trabalhadora na Inglaterra. São Paulo: Boitempo, 2008.

GOULD S. J. Posture maketh the man. Monthly Review, v. 47, n. 6, p. 16, 1995B.

HOBSBAWM, E. J. A era das revoluções. 10. ed. Rio de Janeiro: Paz e Terra, 1997

HOBSBAWM, E. J.; WRIGLEY, C. Industry and Empire: from 1750 to the Present Day. The New Press, 1999.

KURZGESAGT. "The Rise of the Machines - Why Automation Is Different This Time." YouTube, YouTube, 8 June 2017, www.youtube.com/watch?v=WSKi8HfcxEk.

MARX, K. 0 Capital: Crítica da Economia Política, São Paulo: Nova Cultural, 1996. Livro I e II e III, 5 v. (Os Economistas).

MARX, K. Grundrisse: manuscritos econômicos de 1857-58: esboços da crítica da economia política. São Paulo: Boitempo, 2011.

MARX, K. Mathematical Manuscripts of Karl Marx. New park, 1983.

MARX, K. Teorías sobre la plusvalía: tomo IV de El capital. México D.F.: Fondo de Cultura Económica, 1980.

MARX, K. Contribuição a crítica da economia política. $2^{\underline{a}}$ ed. São Paulo: Expressão Popular, 2008. 285p.

MARX, K.; ENGELS, Fr. Manifesto comunista. Boitempo Editorial, 1998. OECD (2017), Gross domestic spending on R\&D (indicator). doi:

10.1787/d8b068b4-en (Acceso em 22 nov. 2017) 
ROSA, L. P. Tecnociências e humanidades: novos paradigmas, velhas questões, o determinismo newtoniano na visão de mundo moderna. São Paulo: Paz e Terra, 2005.

ROSENBERG, N. Por dentro da caixa preta: tecnologia e economia. Campinas: Editora da Unicamp, 2006.

SANTOS, T. Revolução Científico-Técnica e Capitalismo Contemporâneo. Petrópolis: Vozes, 1983.

SANTOS, T. Revolução Científico-Técnica e Acumulação de Capital. Petrópolis: Vozes,1987.

SANTOS, T. Mudanças tecnológicas e economia mundial. Manuscritos - $\mathrm{n}^{\mathbf{0}} \mathbf{3}$, 2002. p. 62.

SANTOS, T. Por uma Economia Política da Ciência e Tecnologia. Revista Ciência \& Luta de Classes (digital), Rio de Janeiro, Editora Inverta, n.1, vol 1, julho de 2014 pp. 45- 54. 